\title{
DEVELOPMENT AND EVALUATION OF CONTROLLED RELEASE FORMULATION OF LAMIVUDINE BASED ON MICROPOROUS OSMOTIC TABLET TECHNOLOGY USING FRUCTOSE AS OSMOGEN
}

\author{
Chinmayakeshari sahoo ${ }^{1 *}$, Surepalli Ram Mohan Rao ${ }^{2}$, Muvvala Sudhakar ${ }^{3}$
}

\begin{abstract}
1Pharmaceutics Department, Faculty of Pharmacy, University College of Technology, Osmania University, Hyderabad, Telangana-500007. ${ }^{2}$ Chemical Engineering, Mekelle Institute of Technology, Mekelle University, MekelleEthiopia, PO Box 231.

3Department of Pharmaceutics, Malla Reddy College of Pharmacy,

Maisammaguda, Secunderabad, Telangana-500014.
\end{abstract}

Submitted:02-05-2017

Revised:30-05-2017

Accepted:21-07-2017

*Corresponding author

Chinmayakesharisahoo

Email:sahoo.chinmaya83@gmail.com

\section{INRODUCTION}

Controlled release dosage forms offer prolong drug release of active ingredients at a predetermined rate and a predetermined time (Presscott, 1989) Among various controlled drug delivery systems osmotic controlled drug delivery system (OCDDS) utilizes the principle of osmotic pressure for controlled delivery of active ingredients. The drug released from OCDDS is independent of $\mathrm{pH}$ and hydrodynamic condition of the body and agitation intensity (Kaushal et al., 2003). The present study is to develop controlled porosity osmotic pump (CPOP) tablets of lamivudine. The delivery system of the drug comprises a core with the drug surrounded by a semipermeable membrane (SPM) which is accomplished with different channeling agents of water soluble additives in the coating membrane. The core is coated with cellulose acetate containing in situ micro pore former sorbitol. Further for increasing drug release fructose of $355 \mathrm{~atm}$ was chosen as osmotic agent to generate high osmotic pressure gradient in CPOP. When CPOP tablets placed in a biological system of fluid low levels of water soluble additives are leached from polymer materials which form a sponge like structure in the controlled porosity walls. The rate of drug delivery depends upon the factors (Zenter et al., 1985) such as water permeability of the SPM, osmotic pressure of core formulation, thickness and the total area of the coating.

Human immunodeficiency virus infection/acquired immune deficiency syndrome (HIV/AIDS) is a disease of the human immune system caused by infection with human immune deficiency virus. It is 
called AIDS when a person infected with HIV has a CD4+ count of declines up to 200cells $/ \mu \mathrm{L}$ in the blood (Sahoo et al., 2017). AIDS is transmitted by via unprotected sexual intercourse, contaminated blood transfusions, hypodermic needles and from mother to child during pregnancy, delivery or breastfeeding. The prevention of HIV infection primarily through safe sex using condoms, needle exchange programs awareness required to control the spread of disease and may lead to a near normal life expectancy (Sahoo et al., 2015). The management of AIDS can be controlled by antiretroviral therapy, male circumcision, needle exchange program, use of diaphragms, topical protection, use of condoms and alternative medicine.

Lamivudine is a synthetic nucleoside analogue and is phosphorylated intra cellularly to its active 5'-triphosphate metabolite, lamivudine triphosphate (L-TP). This nucleoside analogue is incorporated into viral DNA by HIV reverse transcriptase resulting in DNA chain termination (Richman, 2001). The present research aimed to design CPOP tablets of lamivudine by wet granulation method containing a dose of $300 \mathrm{mg}$ once daily. Lamivudine has a bioavailability of $86 \%$, protein binding of $36 \%$ and the biological halflife is between 5-7h. Hence it can be given to control the concentration of drug at the site of action. The main objective of the present study was to develop controlled porositybased osmotically controlled release tablets of lamivudine

\section{MATERIALS AND METHODS Materials}

Lamivudine was obtained from Hetero Drugs Pvt. Ltd. India., fructose and mannitol were obtained from Qualigens Fine Chemicals, India. Cellulose acetate (CA) was obtained from Eastman Chemical Inc, Kingsport, TN. Sorbitol, magnesium stearate, talc, HPMCE5LV and polyethylene glycol (PEG) 400, 600, 4000, 6000 were purchased from S.D. Fine Chemicals Ltd, Mumbai, India., Microcrystalline cellulose (MCC) and starch were purchased from Signet Pharma, Mumbai, India. All other solvents and reagents used were of analytical grade.

\section{Compatibility studies DSC}

Physical mixtures of drug and individual excipients in the ratio of 1:1 were taken and examined in DSC. Individual samples as well as a physical mixture of drug and excipients were weighed to about $5 \mathrm{mg}$ in DSC pan (Shimadzu DSC-50, Japan). The sample in the pan was scanned (Kumaravelrajan et al., 2011) in the temperature range of $50-300^{\circ} \mathrm{C}$. The heating rate of $20^{\circ} \mathrm{C} \mathrm{min}^{-1}$ was used and the thermogram obtained was reviewed for evidence of any interactions. Then the themograms were compared with pure samples versus optimized formulation.

\section{Preparation of lamivudine CPOP tablets}

The tablets were prepared by wet granulation technique (Sahoo et al., 2016). Accurately weighed quantities of ingredients (Table Ia) were passed through sieve No. 30. Lubricant (magnesium stearate), a glidant (talc) were passed through sieve No. 80. The ingredients were manually blended homogenously in a mortar by way of geometric dilution without the addition of except lubricant and glidant. The mixture was moistened with an aqueous solution and granulated through sieve No.30 and dried in a hot air oven at $60^{\circ} \mathrm{C}$ for sufficient time (3-4h). The dried granules were passed through sieve No.30 and blended with talc and magnesium stearate. The homogenous blend was then compressed into round tablets with standard concave punches using 10 station rotary compression machine (Minipress, Karnavati, India).

\section{Coating of core tablets}

Table Ib summarizes the components of the coating solution. The coatings of tablets were performed by spray pan coating (Sahoo et al., 2012) in a perforated pan (GAC-205, Gansons Ltd, Mumbai, India). Initially tablets were pre heated by passing hot air through the tablet bed and by rotating at a lower speed of 5-8rpm. The coating process was started with a rotation speed of 10-12 rpm. The spray rate and atomizing air pressure were $4-6 \mathrm{~mL} / \mathrm{min}$ and $1.75 \mathrm{~kg} / \mathrm{cm}^{2}$ respectively. Inlet and outlet air temperature were $50^{\circ} \mathrm{C}$ and $40^{\circ} \mathrm{C}$ respectively, coated tablets were dried at $50^{\circ} \mathrm{C}$ for $12 \mathrm{~h}$. 
Table Ia. Composition of lamivudine CPOP tablets

\begin{tabular}{ccccccccc}
\hline $\begin{array}{c}\text { Formulation } \\
\text { code }\end{array}$ & $\begin{array}{c}\text { LM } \\
\mathbf{( m g )}\end{array}$ & $\begin{array}{c}\text { MCC } \\
\mathbf{( m g )}\end{array}$ & $\begin{array}{c}\text { Starch( } \\
\mathbf{m g})\end{array}$ & $\begin{array}{c}\text { HPMC } \\
\text { E5LV(mg) }\end{array}$ & $\begin{array}{c}\text { Fructose } \\
\text { (mg) }\end{array}$ & $\begin{array}{c}\text { Magnesium } \\
\text { stearate } \\
\text { (mg) }\end{array}$ & $\begin{array}{c}\text { Talc } \\
\text { (mg) }\end{array}$ & $\begin{array}{c}\text { Total wt. } \\
\text { (mg) }\end{array}$ \\
\hline LF1 & 300 & 190 & 25 & 100 & 25 & 5 & 5 & 650 \\
LF2 & 300 & 165 & 25 & 100 & 50 & 5 & 5 & 650 \\
LF3 & 300 & 140 & 25 & 100 & 75 & 5 & 5 & 650 \\
LF4 & 300 & 115 & 25 & 100 & 100 & 5 & 5 & 650 \\
\hline
\end{tabular}

Table I b. Coating composition for CPOP tablets

\begin{tabular}{cccccccc}
\hline $\begin{array}{c}\text { Formulation } \\
\text { code }\end{array}$ & $\begin{array}{c}\text { CA } \\
(\mathbf{g})\end{array}$ & $\begin{array}{c}\text { PEG 400 } \\
(\mathbf{g})\end{array}$ & $\begin{array}{c}\text { PEG 600 } \\
\mathbf{( g )}\end{array}$ & $\begin{array}{c}\text { PEG } \\
\mathbf{4 0 0 0}(\mathbf{g})\end{array}$ & $\begin{array}{c}\text { PEG 6000 } \\
(\mathbf{g})\end{array}$ & $\begin{array}{c}\text { Sorbitol } \\
(\mathbf{g})\end{array}$ & $\begin{array}{c}\text { Acetone } \\
(\mathbf{m L})\end{array}$ \\
\hline LF1 & 6 & 2 & 0 & 0 & 0 & 0 & 300 \\
LF2 & 6 & 0 & 2 & 0 & 0 & 0.4 & 300 \\
LF3 & 6 & 0 & 0 & 2 & 0 & 0.8 & 300 \\
LF4 & 6 & 0 & 0 & 0 & 2 & 1.2 & 300 \\
\hline
\end{tabular}

\section{Evaluation of CPOP tablets \\ Pre compression parameters of CPOP granules (Sahoo et al.,2015) \\ Angle of repose $(\theta)$}

The flow property of granules was determined by measuring the angle of repose where the granules were allowed to flow through funnel freely onto the clean surface. The funnel was fixed at such a height that bottom tip of the funnel should not touch apex of the heap of granules. The angle of repose is calculated using the following equation:

$\tan \theta=\mathrm{h} / \mathrm{r}$

$\theta=\tan ^{-1}(\mathrm{~h} / \mathrm{r})$

Where $\theta$ is the angle of repose, h is the height of heap in $\mathrm{cm}$ and $\mathrm{r}$ is the radius of the circular support (cone) in $\mathrm{cm}$. According to the specifications the angle of repose value less than $25^{\circ} \mathrm{C}$ indicates excellent flow whereas angle greater than $40^{\circ} \mathrm{C}$ indicates poor flow.

\section{Bulk density ( $e_{\text {bulk }}$ )}

Bulk density is determined by pouring the granules into a graduated cylinder of bulk density apparatus (Sisco, India). The bulk volume $\left(V_{\text {bulk }}\right)$ and mass $(m)$ of the granules are determined. The bulk density is calculated by using the following formula.

$\mathrm{e}_{\mathrm{bulk}}=\frac{\mathrm{m}}{\text { Vbulk }}$.

\section{Tapped density ( $\left.\mathbf{e}_{\text {tap }}\right)$}

The measuring cylinder containing a known mass of granules blend is tapped 1000 times for a fixed time in tap density tester (Sisco, India). The minimum volume occupied in the cylinder $\left(V_{\text {tap }}\right)$ and mass of the granules (m) are measured. The tapped density is measured by using the following formula.

$\mathrm{e}_{\mathrm{tap}}=\frac{\mathrm{m}}{\mathrm{Vtap}}$......

\section{Compressibility index (Carr's index)}

The compressibility index determines the flow property characteristics (Patel et al., 2012) of granules developed by Carr. The Carr's index can be calculated by the following formula.

$\%$ Carr's index $=\frac{\text { etap }- \text { ebulk }}{\text { etap }} \times 100$

Where $e_{\text {tap }}$ is the tapped density of granules and ebulk is the bulk density of granules.

According to the specifications the Carr's index values between 5-15 indicates excellent flow whereas between 12-16 indicates good flow. Values between 18-21 indicate fair passable whereas between 23-35 indicates poor and values between 33-38 indicates very poor and greater than 40 indicates extremely poor.

\section{Hausner's ratio $\left(H_{R}\right)$}

Hausner's ratio is used for the determination of flow properties of granules. 
The Hausner's ratio can be calculated by the following formula

$\mathrm{H}_{\mathrm{R}}=\frac{\text { etap }}{\text { ebulk }}$.

According to specifications values less than 1.25 indicate good flow ( $=20 \%$ of Carr's index) whereas greater than 1.25 indicates poor flow ( $=33 \%$ of Carr's index).

\section{Post compression parameters of CPOP tablets (Sahoo et al.,2015) Thickness}

The thickness of individual tablets is measured by using Vernier caliper (Absolute digimatic, Mitutoyo Corp. Japan) which gives the accurate measurement of thickness in $\mathrm{mm}$. The limit of the thickness deviation of each tablet is $\pm 5 \%$.

\section{Coat thickness}

After dissolution the film was isolated from the tablets and dried at $40^{\circ} \mathrm{C}$ for 1 hr. Thickness was measured by using electronic digital calipers (Absolute digimatic, Mitutoyo Corp. Japan) and mean values were taken.

\section{Hardness test}

The hardness of tablets can be determined by using Monsanto hardness tester (Sisco, India) and measured in terms of $\mathrm{kg} / \mathrm{cm}^{2}$.

\section{Friability test}

Friability of tablets was performed in a Roche friabilator (Sisco, India). Ten tablets (Edavalath et al., 2011) were initially weighed $\left(\mathrm{W}_{\text {initial }}\right)$ together and then placed in the chamber. The friabilator was operated for 25 revolutions for 4 minsand the tablets are then dusted and reweighed $\left(\mathrm{W}_{\text {final }}\right)$. The percentage of friability was calculated using the following equation.

$\%$ Friability $=\mathrm{F}=\left(1-\frac{\text { Wfinal }}{\text { Winitial }}\right) \times 100 \ldots .(7)$

Where, $W_{\text {initial }}$ and $W_{\text {final }}$ are the weight of the tablets before and after the test respectively.

\section{Weight variation test}

The weight variation test is done by weighing 20 tablets individually in weighing balance (Shimadzu, Japan) calculating the average weight (Maheswari et al., 2012) and comparing the individual tablet weights to the average. The percentage weight deviation was calculated and then compared with USP specifications.

\section{Uniformity of drug content test}

Ten tablets were weighed and powdered by mortar. Drug content (USP, 2003, Pragathi et al., 2015) for tablets was done by the assay method. An accurately weighed equivalent weighed quantity of powdered tablet was dissolved in $0.1 \mathrm{~N} \mathrm{HCl}$ using magnetic stirrer (Ricon, Hyderabad, India) in a volumetric flask for $24 \mathrm{~h}$. The solution was filtered through Whatman filter paper No.1 and analyzed spctrophotometrically at $280 \mathrm{~nm}$ (Shimadzu UV-1800, Japan).

\section{Diameter of tablet}

The diameter of individual tablets is measured by using vernier caliper (Absolute digimatic, Mitutoyo Corp. Japan)in mm.

\section{In vitro dissolution studies}

In vitro dissolution test (Kanagale et al., 2007) was carried out by using USP type II (paddle) apparatus at $75 \mathrm{rpm}$ in $900 \mathrm{~mL}$ of dissolution fluid of $0.1 \mathrm{~N} \mathrm{HCl}$ for first 2 hours and phosphate buffer $\mathrm{pH} 6.8$ from 3 to $12 \mathrm{~h}$ maintained at $37 \pm 0.5^{\circ} \mathrm{C}$. At specified time intervals $5 \mathrm{~mL}$ aliquot of the solution was withdrawn through $0.45-\mu \mathrm{m}$ cellulose acetate filter from the dissolution apparatus (Sahoo et al., 2017) with the replacement of fresh fluid to dissolution medium. The filtered solution is diluted and analyzed spectrophotometrically at $280 \mathrm{~nm}$ for $0.1 \mathrm{~N} \mathrm{HCl}(\mathrm{pH} 1.2)$ and $270 \mathrm{~nm}$ for phosphate buffer $\mathrm{pH} 6.8$.

\section{Mathematical modeling of in vitro drug release(IVDR)kinetics}

For the determination of the drug release kinetics (Sahoo et al., 2015) from the porous osmotic pump tablet, the in vitro release data were analyzed by zero order, first order, Higuchi, Korsmeyer and Peppas and HixsonCrowell equations.

Zero order kinetics can be expressed by the equation

$\mathrm{Q}_{\mathrm{t}}=\mathrm{Q}_{0}-\mathrm{K}_{0} \mathrm{t}$

Where

$\mathrm{Q}_{\mathrm{t}}$ is the amount of drug dissolved in time $\mathrm{t}, \mathrm{Q}_{0}$ is the initial amount of drug in the solution and $\mathrm{K}_{0}$ is the zero order release constant. 
First order kinetics can be expressed by the equation:

$\log C=\log \mathrm{C}_{0}-\mathrm{K}_{1} \mathrm{t} / 2$

Where $\mathrm{C}_{0}$ is the initial concentration of the drug, $\mathrm{C}$ is the amount of drug remaining to be released in time $t, K_{1}$ is the first order release constant.

Higuchi's classical diffusion equation (Higuchi, 1963) can be expressed as

$\mathrm{Q}=\mathrm{K}_{\mathrm{H}} \sqrt{ } \mathrm{t}_{\mathrm{O}}$

Where $\mathrm{Q}$ is the amount of drug release in time $\mathrm{t}, \mathrm{K}_{\mathrm{H}}$ is the Higuchi dissolution constant.

Korsmeyer-Peppas model (KP Model) for the drug release (Korsmeyer et al., 1983) for this model is expressed as

$\log \left(\mathrm{M}_{\mathrm{t}} / \mathrm{M}_{\infty}\right)=\log \mathrm{K}+\mathrm{n} \log \mathrm{t}$

Where $M_{t}$ is the amount of drug release at time $t, M_{\infty}$ is the amount of drug release after an infinite time, $\mathrm{K}$ is the release rate constant incorporating structural and geometric characteristics of the tablet and $n$ is the release exponent indicative of mechanism of drug release.

Hixson and Crowell model (Hixson, 1931) is expressed by the equation

$\mathrm{W}_{0}{ }^{1 / 3}-\mathrm{W}_{\mathrm{t}}^{1 / 3}=x \mathrm{t}$

Where $W_{0}$ is the initial amount of drug in the pharmaceutical dosage form, $\mathrm{W}_{\mathrm{t}}$ is remaining amount of drug in the pharmaceutical dosage form at time $\mathrm{t}$ and $x$ is proportionality constant incorporating the surface volume relation.

\section{Effect of osmogen concentration}

To check the effect of osmogen (Shah et al., 2013) concentration on drug release formulations were prepared with the different concentration of osmotic agents (Sahoo et al., 2017) and all other parameters of tablet kept constant. The drug release was compared with the different osmogen concentration of formulated batches by using USP-II dissolution apparatus.

\section{Effect of pore former concentration}

Different concentrations of pore former (Dasankoppa et al., 2013) are used in SPM formation. In order to compare the effect of different concentrations of pore formers in vitro release profiles as well as a number of formation of micro pores are compared.

\section{Effect of coating thickness}

The tablet is kept in $900 \mathrm{~mL}$ of dissolution fluid $0.1 \mathrm{~N} \mathrm{HCl}$ for first $2 \mathrm{~h}$ and next followed by 3 to $12 \mathrm{~h}$ in phosphate buffer $\mathrm{pH}$ 6.8 of USP type II dissolution apparatus at 75 $\mathrm{rpm}$ and maintaining the temperature $37 \pm 0.5^{\circ} \mathrm{C}$ of dissolution media to check the effect of membrane thickness (Sahoo et al., 2017). The sample $5 \mathrm{~mL}$ was withdrawn through $0.45-\mu \mathrm{m}$ cellulose acetate filter at different time intervals replaced with fresh medium and analyzed in UV-Visible spectrophotometer.

\section{Effect of osmotic pressure}

The effect on osmotic pressure (Rani et al., 2004) on the optimized formulation was studied in media of different osmotic pressure and the release profile with varying osmotic pressure is compared. To increase the osmotic pressure of the release media mannitol (Sahoo et al., 2017) was added to produce $30 \mathrm{~atm}, 60$ atm and 90 atm respectively.

\section{Effect of pH}

In order to study the effect of $\mathrm{pH}$ of release medium in the drug release of optimized formulation, the in vitro release study was carried in dissolution media having different pH media (Patel et al., 2012). Dissolution can be carried in $900 \mathrm{~mL}$ of $0.1 \mathrm{~N} \mathrm{HCl}(\mathrm{pH} 1.2), \mathrm{pH}$ 6.8 and phosphate buffer $\mathrm{pH} 7.4$ in USP type II dissolution apparatus at $75 \mathrm{rpm}$ with maintaining the temperature at $37 \pm 0.5^{\circ} \mathrm{C}$. The sample $(5 \mathrm{~mL})$ was withdrawn at predetermined intervals and analyzed after filtration through $0.45-\mu \mathrm{m}$ cellulose acetate filter.

\section{Effect of agitation intensity}

The drug release of optimized formulation was subjected to dissolution at various rotation speeds (Verma et al., 2004) to demonstrate the effect of agitation intensity. Dissolution was carried out in USP-II (Paddle) at 50, 100 and $150 \mathrm{rpm}$. The samples were withdrawn at predetermined intervals through $0.45-\mu \mathrm{m}$ cellulose acetate filter and analyzed by UV-Visible spectrophotometer. 


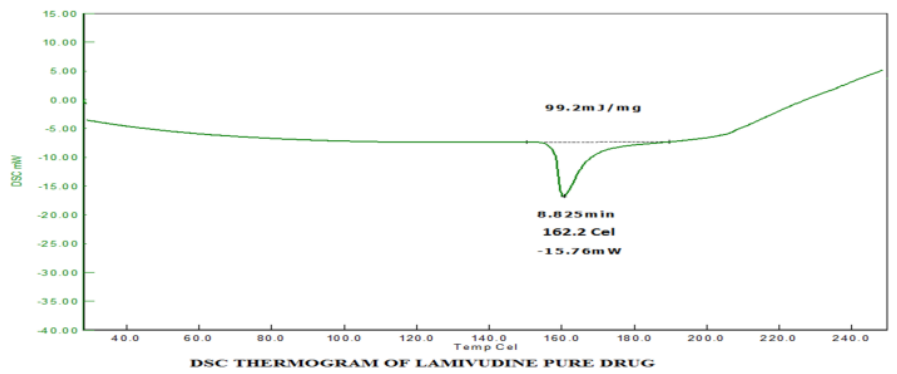

Figure 1a. DSC thermogram of lamivudine

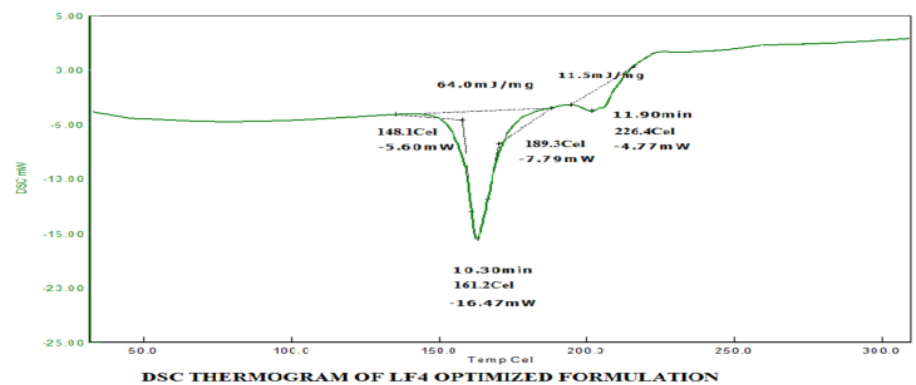

Figure 1b. DSC thermogram of LF4

\section{Scanning electron microscopy study}

In order to observe the mechanism of drug release and surface morphology (Rao et al., 2009) from the developed formulations surface coated tablets before and after dissolution studies was examined using scanning electron microscope (Leica, Bensheim, Switzerland).

\section{Accelerated stability studies}

The formulation was subjected to accelerated stability studies (Sharma et al., 2014) as per ICH (The International Conference of Harmonization) guidelines. The packed tablets in air tight container were placed in stability chambers (Thermo lab Scientific equipment Pvt. Ltd., Mumbai, India) maintained at $40 \pm 2^{\circ} \mathrm{C}, 75 \pm 5 \%$ RH for 3 months. Tablets were periodically removed and evaluated for physical characteristics, drug content, in vitro drug release etc.

\section{RESULTS ANS DISCUSSION DSC thermograms}

DSC thermo gram showed an endothermic peak at $162.2^{\circ} \mathrm{C}$ which is the corresponding melting point of drug (Figure 1a). DSC thermo gram showed an endothermic peak at $161.2^{\circ} \mathrm{C}$ in the $\mathrm{LF} 4$ formulation (Figure 1b). From the above DSC studies it was observed that the formulation is thermodynamically stable. No shifting of peaks from endothermic to exothermic was also noticed. Hence physical mixture showed that there was compatibility with the drug.

\section{Pre compression parameters}

The angle of repose of pre-compression blends of various batches was in the range of $25.01 \pm 0.12$ to $28.78 \pm 0.14$. The bulk density of pre-compression blends was found to be in the range of $0.524 \pm 0.14$ to $0.528 \pm 0.12 \mathrm{~g} / \mathrm{mL}$, tapped density in the range of $0.558 \pm 0.06$ to $0.571 \pm 0.12 \mathrm{~g} / \mathrm{mL}$, the Carr's index values were in the range of $5.73 \pm 0.05$ to $8.05 \pm 0.14$, and Hausner's ratio values were ranges of $1.06 \pm 0.03$ to $1.08 \pm 0.11$. So the results of pre compression parameters such as angle of repose, bulk density, tapped density, Carr's index, and Hausner's ratio indicated that the dry granules of all the formulations of lamivudine showed excellent flow properties which favor easy manufacturing of CPOP tablets under study (Table IIa). 
Table IIa. Pre compression parameters of CPOP granules

\begin{tabular}{cccccc}
\hline $\begin{array}{c}\text { Formulation } \\
\text { code }\end{array}$ & $\begin{array}{c}\text { Angle of } \\
\text { repose } \\
\text { (degree) } \\
\text { S.D } \pm\end{array}$ & $\begin{array}{c}\text { Bulk density } \\
(\mathbf{g} / \mathbf{m L})^{\mathbf{a} \pm} \\
\text { S.D }\end{array}$ & $\begin{array}{c}\text { Tapped } \\
\text { density } \\
(\mathbf{g} / \mathbf{m L})^{\mathbf{a}} \pm \\
\text { S.D }\end{array}$ & $\begin{array}{c}\text { Carr's } \\
\text { Index } \\
(\%))^{\mathbf{a}} \pm \text { S.D }\end{array}$ & $\begin{array}{c}\text { Hausner'sRatio } \pm \\
\text { S.D }\end{array}$ \\
\hline LF1 & $28.78 \pm 0.14$ & $0.528 \pm 0.12$ & $0.562 \pm 0.11$ & $6.05 \pm 0.14$ & $1.06 \pm 0.09$ \\
LF2 & $27.82 \pm 0.12$ & $0.524 \pm 0.14$ & $0.567 \pm 0.12$ & $7.58 \pm 0.12$ & $1.08 \pm 0.11$ \\
LF3 & $26.19 \pm 0.11$ & $0.525 \pm 0.11$ & $0.571 \pm 0.12$ & $8.05 \pm 0.14$ & $1.08 \pm 0.09$ \\
LF4 & $25.01 \pm 0.12$ & $0.526 \pm 0.04$ & $0.558 \pm 0.06$ & $5.73 \pm 0.05$ & $1.06 \pm 0.03$ \\
\hline
\end{tabular}

N.B.-All values are expressed as mean \pm S.D, ${ }^{a} \mathrm{n}=3$

Table IIb. Post compression parameters of lamivudine CPOP tablets

\begin{tabular}{|c|c|c|c|c|c|c|c|}
\hline $\begin{array}{l}\text { Formulation } \\
\text { code }\end{array}$ & $\begin{array}{c}\text { Thickness } \\
(\mathrm{mm})^{\mathrm{a}} \pm \\
\text { S.D }\end{array}$ & $\begin{array}{c}\text { Coat } \\
\text { thickness } \\
(\mu \mathrm{m})^{\mathrm{a}} \pm \mathrm{S} . \mathrm{D}\end{array}$ & $\begin{array}{l}\text { Hardness } \\
\left(\mathrm{kg} / \mathrm{cm}^{2}\right)^{\mathrm{a}} \\
\pm \text { S.D }\end{array}$ & $\begin{array}{c}\% \\
\text { Friability } \\
(\%)^{\mathrm{b}} \pm \\
\text { S.D }\end{array}$ & $\begin{array}{c}\text { Average } \\
\text { wt.of tablet } \\
(\mathrm{mg})^{\mathrm{b}} \pm \mathrm{S} . \mathrm{D}\end{array}$ & $\begin{array}{c}\% \text { Drug } \\
\text { content }(\%)^{\mathrm{a}} \\
\pm \mathrm{S} . \mathrm{D}\end{array}$ & $\begin{array}{c}\text { Diameter } \\
(\mathrm{mm})^{\mathrm{a}} \pm \\
\text { S.D }\end{array}$ \\
\hline LF1 & $3.571 \pm 0.02$ & $251.1 \pm 3.2$ & $7.6 \pm 0.12$ & $0.17 \pm 0.05$ & $649.09 \pm 1.03$ & $99.219 \pm 1.15$ & $12.13 \pm 0.05$ \\
\hline LF2 & $3.567 \pm 0.03$ & $200.8 \pm 3.1$ & $7.9 \pm 0.01$ & $0.19 \pm 0.04$ & $651.08 \pm 1.04$ & $98.69 \pm 1.03$ & $11.98 \pm 0.06$ \\
\hline LF3 & $3.509 \pm 0.01$ & $150.5 \pm 2.6$ & $8.0 \pm 0.02$ & $0.12 \pm 0.12$ & $650.07 \pm 1.03$ & $98.958 \pm 1.06$ & $12.29 \pm 0.03$ \\
\hline LF4 & $3.503 \pm 0.02$ & $100.3 \pm 2.4$ & $8.1 \pm 0.04$ & $0.11 \pm 0.13$ & $650.04 \pm 1.1$ & $99.47 \pm 1.25$ & $12.2 \pm 0.07$ \\
\hline
\end{tabular}

N.B.-All values are expressed as mean \pm S.D, ${ }^{\mathrm{a}} \mathrm{n}=10,{ }^{\mathrm{b}} \mathrm{n}=20$

Table III. Fitting of IVDR data in various mathematical models

\begin{tabular}{cccccccccccc}
\hline Models & \multicolumn{2}{c}{ Zero order } & \multicolumn{2}{c}{ First order } & \multicolumn{2}{c}{ Higuchi } & \multicolumn{3}{c}{ Korsmeyer-Peppas } & \multicolumn{2}{c}{ Hixson-Crowell } \\
\hline Batches & $\mathrm{R}^{2}$ & $\mathrm{~K}_{0}$ & $\mathrm{R}_{1}{ }^{2}$ & $\mathrm{~K}_{1}$ & $\mathrm{R}_{\mathrm{H}^{2}}$ & $\mathrm{~K}_{\mathrm{H}}$ & $\mathbf{R}_{\mathbf{K}}$ & $\mathbf{K}_{\mathbf{k p}}$ & $\mathbf{n}$ & $\mathbf{R}^{\mathbf{2}}$ & $\mathbf{K s}$ \\
\hline LF1 & 0.946 & 6.324 & 0.927 & 0.1658 & 0.972 & 24.77 & 0.941 & 26.061 & 0.458 & 0.961 & 0.181 \\
LF2 & 0.920 & 6.229 & 0.950 & 0.1727 & 0.986 & 24.90 & 0.963 & 29.922 & 0.419 & 0.971 & 0.184 \\
LF3 & 0.903 & 6.274 & 0.954 & 0.1888 & 0.987 & 25.33 & 0.964 & 32.885 & 0.394 & 0.973 & 0.195 \\
LF4 & 0.886 & 6.446 & 0.884 & 0.2487 & 0.982 & 26.21 & 0.953 & 36.728 & 0.368 & 0.956 & 0.229 \\
\hline
\end{tabular}

\section{Post compression parameters}

The thickness of formulated tablets was found to be in the range of $3.503 \pm 0.02$ to $3.571 \pm 0.02 \mathrm{~mm}$, coat thickness in the range of $100.3 \pm 2.4$ to $251.1 \pm 3.2 \mu \mathrm{m}$, the hardness values were in the range of $7.6 \pm 0.12$ to $8.1 \pm 0.04 \mathrm{~kg} /$ $\mathrm{cm}^{2}$, the friability values were in range of $0.11 \pm 0.13$ to $0.19 \pm 0.04$, average weight of tablet was in the range of $649.09 \pm 1.03$ to $651.08 \pm 1.04$ $\mathrm{mg}$, drug content of tablet was in the range of $98.69 \pm 1.03$ to $99.47 \pm 1.25$ and diameter of tablets values were ranges of $11.98 \pm 0.06$ to $12.29 \pm 0.03$ $\mathrm{mm}$. Post compression parameters of all the formulation of lamivudine showed satisfied results according to the Pharmacopoeias specifications (Table IIb).

\section{In vitro drug release study}

The in vitro drug release characteristics were studied in $900 \mathrm{~mL}$ of $0.1 \mathrm{~N} \mathrm{HCl}(\mathrm{pH} 1.2)$ for a period of the first $2 \mathrm{~h}$ and 3 to $12 \mathrm{~h}$ in phosphate buffer $\mathrm{pH} 6.8$ using USP type II dissolution apparatus (Paddle type). The cumulative percentage drug release for LF1, LF2, LF3 and LF4 were 90.54, 91.26, 92.43 and $97.78 \%$ respectively of lamivudine at the end of $12 \mathrm{~h}$. It was observed that the drug release is more in LF4 batch as it contains $100 \mathrm{mg}$ of polymer and $100 \mathrm{mg}$ of fructose. Hence it was confirmed that the drug release depends upon osmotic pressure of osmogen (Figure 2). 


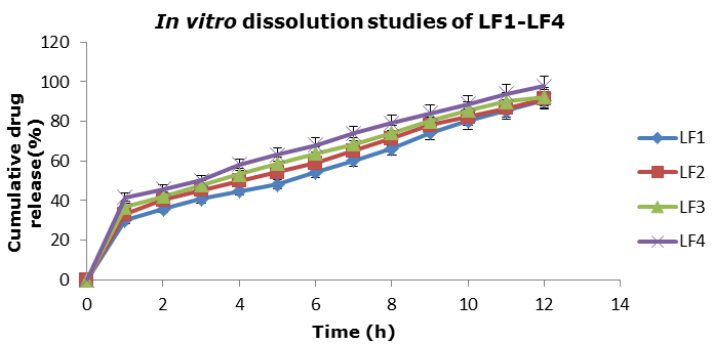

Figure 2. In vitro release profiles showing lamivudine release from various fabricated formulations LF1-LF4

\section{IVDR kinetics}

From the kinetic it is observed that LF1 follows non-Fickian transport mechanism and LF2, LF3 and LF4 show Fickian diffusion mechanism. The regression values of LF1 to LF4 for zero order were 0.946, 0.920, 0.903 and 0.886 respectively. The regression values of LF1 to LF4 for first order were found to be $0.927,0.950,0.954$ and 0.884 respectively. All the formulations showed to be best expressed by Higuchi equation as the plots showed high linearity with regression values closer to unity. The optimized formulation LF4 is showing highest regression values $\left(\mathrm{R}^{2}\right)$ in Higuchi model than zero order and first order. Hence the drug release follows Higuchi kinetics. The $\mathrm{n}$ value for optimized formulation is $0.368(n<0.45)$. Hence it follows Fickian diffusion mechanism (Table III).

\section{Effect of osmogene concentration}

It is observed that osmogene enhances the drug release of drug and thus had a direct effect on drug release. The concentrations of osmogen were $25,50,75$ and $100 \mathrm{mg} /$ tablet for LF1, LF2, LF3 and LF4 respectively. The cumulative percentage drug release for LF1, LF2, LF3 and LF4 were 90.54, 91.26, 92.43 and $97.78 \%$ respectively of lamivudine at the end of 12h. It was observed that the drug release is more in LF4 batch comparing to other batches due to more concentration of osmotic agent (Figure 2).

\section{Effect of pore former}

To study the effect of pore forming agent core formulations of lamivudine were coated with varying coating compositions of pore forming agent containing $0 \%, 6.6 \%$,
$13.3 \%$ and $20 \% \mathrm{w} / \mathrm{w}$ of CA of sorbitol for LF1, LF2, LF3 and LF4 respectively. The drug release order for LF1 to LF4 batch is LF4 $>$ LF3 $>$ LF2 $>$ LF1. The optimized lamivudine CPOP tablets LF4 contain fructose $100 \mathrm{mg} / \mathrm{tab}$ and pore former concentration $20 \% \mathrm{w} / \mathrm{w}$ of CA of sorbitol releases drug $97.78 \%$ up to end of $12 \mathrm{~h}$. It is clearly evident that the level of sorbitol had a direct effect on drug release. As the level of pore former increases the membrane becomes more porous after coming contact with aqueous environment resulting in faster drug release. Statistical analysis (' $\mathrm{t}$ '-test) of drug release data gives $t$ value of 0.03 for an LF4 formulation which is much less compared to the table value of $2.353(p<0.05)$. Hence it can be concluded that osmogen concentration as well as porogen concentration both have a direct relation to drug release of lamivudine (Figure 2).

\section{Effect of membrane thickness}

The coating thickness for LF1, LF2, LF3 and LF4 were 251.1, 200.8, 150.5 and $100.3 \mu \mathrm{M}$ respectively. The drug release is highest $(97.78 \%)$ at the end of $12 \mathrm{~h}$ in LF4 because the thickness of coat is less. Similarly, the drug release is minimum at the end of $12 \mathrm{~h}$ in $\mathrm{LF} 1(90.54 \%)$ as the thickness of coat is more. It is clearly evident that drug release decreases with increase in a coating thickness of the semi permeable membrane Release profile of lamivudine from these formulations (Figure 2).

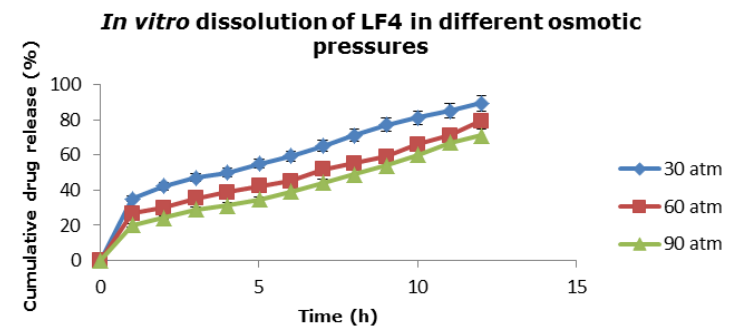

Figure 3. In vitro release profiles showing lamivudine release from best LF4 in different osmotic pressures

\section{Effect of osmotic pressure}

The results of release studies of optimized formulation in media of different osmotic pressure indicated that the drug release is highly dependent on the osmotic pressure of the release media. The release was inversely 
related to the osmotic pressure of release media. This finding confirms that the mechanism of drug release is by osmotic pressure. The drug release for LF4 was found to be $89.36 \%$ for $30 \mathrm{~atm}, 79.24 \%$ for $60 \mathrm{~atm}$ and $70.98 \%$ for 90 atm respectively (Figure 3 ).

\section{Effect of pH}

The optimized formulation LF4 was subjected to in vitro drug release studies in buffers with different $\mathrm{pH}$ media like $0.1 \mathrm{~N} \mathrm{HCl}$ $(\mathrm{pH}$ 1.2), phosphate buffer $\mathrm{pH} 6.8$ and phosphate buffer pH7.4 in USP type II dissolution apparatus in $75 \mathrm{rpm}$. The drug release of optimized formulation was observed in $0.1 \mathrm{~N} \mathrm{HCl}(\mathrm{pH} 1.2)$ for drug release, it was found that the drug release was nearly same for the end of $11 \mathrm{~h}$. But at the end of $12 \mathrm{~h}$ the drug release was same with optimized formulation $97.78 \%$. The drug release of the LF4 formulation was observed in phosphate buffer $\mathrm{pH} 6.8$ for drug release, it was found that the drug release was nearly same for the end of $11 \mathrm{~h}$. But at the end of $12 \mathrm{~h}$ the drug release was same with optimized formulation $97.78 \%$. The drug release of the LF4 formulation was observed in phosphate buffer $\mathrm{pH} 7.4$ for drug release, it was found that the drug release was nearly same for the end of $11 \mathrm{~h}$. But at the end of $12 \mathrm{~h}$ the drug release was same with optimized formulation $97.78 \%$. It is observed that there is no significant difference in the release profile, demonstrating that the developed formulation shows $\mathrm{pH}$ independent release (Figure 4).

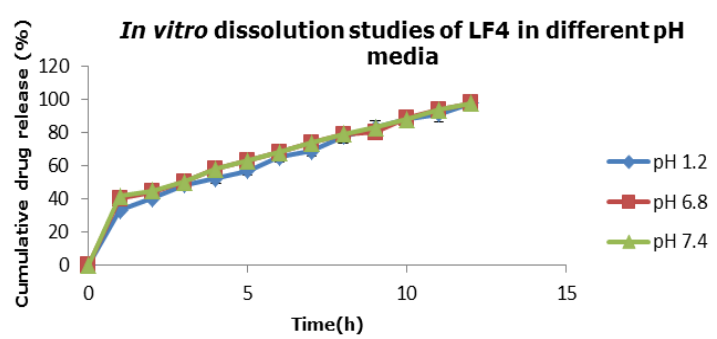

Figure 4. In vitro dissolution study of best formulation $\mathrm{LF} 4$ in various $\mathrm{pH}$ media

\section{Effect of agitation intensity}

The optimized formulation of the LF4 batch was carried out in USP dissolution apparatus type-II at varying rotational speeds $(50,100$ and $150 \mathrm{rpm})$. The drug releases of the optimized formulation were observed in 50, 100 and $150 \mathrm{rpm}$ for drug release, it was found that the drug release was nearly same for the end of $11 \mathrm{~h}$. But at the end of $12 \mathrm{~h}$ the drug release was same with optimized formulation $97.78 \%$. It shows that the release of lamivudine from CPOP is independent of agitation intensity. Hence it is expected that the release from the developed formulation will be independent of the hydrodynamic conditions of the absorption site (Figure 5).

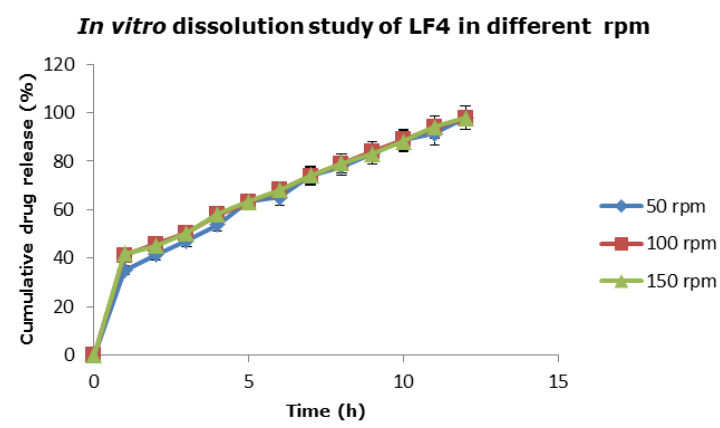

Figure 5. In vitro dissolution study of best formulation LF4 in various agitation speeds

\section{SEM analysis}

SEM study indicates before dissolution fewer pores were found in the coating membrane. But after dissolution comparatively more numbers of pores were found in the membrane might be due to leaching or removal of the entrapped drug from the formulation as well as the presence of pore forming agent sorbitol in the formulation (Figure $6 \mathrm{a}$ and $6 \mathrm{~b}$ ).
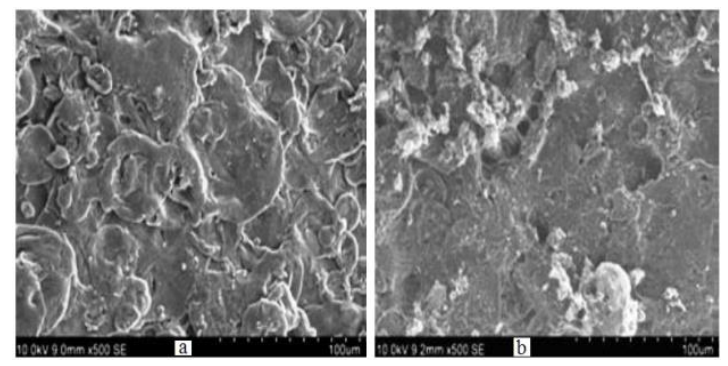

Figure 6a. SEM image of LF4 before dissolution, 6b. SEM image of LF4 after dissolution

\section{Stability studies}

From short term stability studies of optimized formulation LF4, it was confirmed that there was no significance changes in 
physical appearance, thickness, hardness, friability, weight variation and drug content and $\%$ drug release.

\section{CONCLUSION}

Lamivudine CPOP tablets were successfully developed. Out of several formulations LF4 containing 100mg of fructose per core tablet, $100 \mathrm{mg}$ of HPMC E5LV and 1.2 $\mathrm{gm}$ of sorbitol in SPM as pore former was successfully complied with the rate of drug release of CPOP tablets. Thus LF4 can provide more prolong, control and $\mathrm{pH}$ independent drug release and expected to perform therapeutically better with improved patient compliance.

\section{ACKNOWLEDGEMENTS}

The authors would like to acknowledge the contributions of Pharmaceutics department, Faculty of Pharmacy, University College of Technology, Osmania University, Hyderabad, India for providing necessary facilities to cary out the review work. This study was part of a $\mathrm{Ph} . \mathrm{D}$ thesis under Osmania University, Hyderabad.

\section{REFERENCES}

Dasankoppa FS., Ningangowdar M., Sholapur H., 2013. Formulation and evaluation of controlled porosity osmotic pump for oral delivery of ketorolac. J Basic and Clin Pharmacy.4(1):2-9.

Edavalath S., Shivanand K., Prakasam K., Rao BP., Divakar G. 2011. Formulation development and optimization of controlled porosity osmotic pump tablets of diclofenac sodium. Int. J. Pharm. Pharm. Sci. 3(1):80-87.

Higuchi T., 1963. Mechanism of sustained action medication theoretical analysis of rate of release of solid drugs dispersed in solid matrices. J Pharm Sci52:1145-1149

Hixson AW., Crowell JH., 1931.Dependence of reaction velocity upon surface and agitation, Ind.Eng.Chem. 23:923-931.

Kaushal AM., Garg S., 2003.An update on osmotic drug delivery patents. Pharm. Tech., 27: 38-44

Kumaravelrajan R.,Narayanan N., Suba V., 2011. Development and evaluation of controlled porosity osmotic pump for
Nifedipine and Metoprololcombination. Lipids in Health and Disease. 10:51

Kanagale P., Lohray BB., Misra A., Davadra P., Kini R., 2007. Formulation and Optimization of Porous Osmotic Pump based Controlled Release System of Oxybutynin. AAPS Pharm SciTech. 8(3): E1-E7

Korsmeyer RW., Gunny R., Docler E., Buri P., Peppas NA., 1983. Mechanism of solute release from porous hydrophilic polymers Int.J.Pharm.15:25-35

Maheswari U., Elango K., Chellakumari D., Saravanan K., Samy AJ., 2012. Formulation and evaluation of controlled porosity osmotic tablets of lornoxicam. Int. J.Pharm Scie Res 3(6):1625-1631.

Pragathi NA et al., 2015.Effect of different diluents on release profile of Lamivudine from sustained release matrix tablet using kollidon SR as release retardant, Int.J.Res. Pharm. and Nano Sciences, 4(2): 50-59.

Presscott LF., 1989. The need for improved drug delivery in clinical practice in Novel Drug Delivery and its Therapeutic applications. West Susset, UK: John Wiley and Sons; 1-11.

Patel H., Patel UD., Kadikar H., Bhimani B., Daslaniya D., Patel G., 2012. Formulation and evaluation of controlled porosity osmotic pump tablets of glimepiride. Inter $J$ Drg Del4(1):113-24.

Patel H., Patel MM., 2012. Formulation and evaluation of controlled porosity osmotic drug delivery system of carvedilol phosphate. J PharmScie Bioscie Res2(2):77-82.

Rani M., Mishra B., 2004.Comparative in vitro and in vivo evaluation of matrix,osmotic matrix and osmotic pump tablets for controlled delivery of diclofenacsodium. AAPSPharm.Sci Tech.5(4):1-7.

Rao BP., Geetha M., Purushothama N., Sanki U., 2009. Optimization and development of swellable controlled porosity osmotic pump tablet for theophylline. Trop. J. Pharm Res. 8(3):247-255.

Richman DD., 2001. HIV chemotherapy. Nature 410, 995-1001, 2001 
Sahoo CK., Sahoo TK., Moharana AK., Panda KC., 2012. Formulation and optimization of porous osmotic pump based controlled release system of Residronate sodium for the treatment of postmenopausal osteoporosis. Int. J PharmScie Rev Res12(1):118-122.

Sahoo CK., Sahoo NK., Rao SRM., Sudhakar M., Satyanarayana K., 2015. Areview on controlled porosity osmotic pump tablets and its evaluation. Bulletin of Faculty of Pharmacy,Cairo University, 53(2):195-205.

Sahoo CK., Rao SRM., Sudhakar M., 2015. Evaluation of controlled porosity osmotic pump tablets a review. Research J. Pharm. And Tech. 8(12):119-125.

Sahoo CK., Rao SRM., Sudhakar M., Kokkula S., 2015. The kinetic modeling of drug dissolution for drug delivery systems: an overview.Der Pharmacia Lettre 7(9):186194.

Sahoo CK., Sahoo NK., Rao SRM., Sudhakar M., 2017. A review on prevention and treatment of AIDS. Pharm Pharmacol Int J.5(1):00108.

Sahoo CK., Rao SRM., Sudhakar M., 2015.A review on human immunity system and HIV infection. Int. J.Current Pharmacentical Review and research 6(6):262-268.

Sahoo CK., Rao SRM., Sudhakar M., 2017. Formulation and optimization of controlled porosity osmotic pump tablets of zidovudine using mannitol as osmogen for the treatment of AIDS. International J. Chem. Tech. Research. 10(5): 216-235.

Sahoo CK., Rao SR., Sudhakar M., Shashikala P., 2017. Formulation and optimization of controlled porosity osmotic pump tablets of ritonavir.J. of Chemical and Pharmaceutical Sciences.10(3):1345-1352.

Sahoo CK., Rao SRM., Sudhakar M., 2017. Formulation and optimization of controlled porosity osmotic pump tablets of zidovudine and lamivudine combination using fructose as osmogen. Journal of Drug Delivery and Therapentics.7(4):41-50.

Sahoo CK., Rao SRM., Sudhakar M., Satyanarayana K., 2017. Development and evaluation of controlled release formulation of zidovudine based on microporous osmotic tablet technology using fructose as osmogen. Research J. Pharm. and Tech. 10(5):1459-1470.

Sahoo CK., Rao SRM., Sudhakar M., Bhaskar J., 2016. Advances in granulation technology. Research J. Pharm. and Tech. 9(5):571-580.

Sharma F., Jain H., Kanzariya V., Upadhyay U., 2014. Formulation and evaluation of controlled release osmotic tablet of metoprololsuccinate. Asian J. Pharm Clin Res7(3):38-43.

Shah N., Patel K., 2013. Design and development of controlled porosity osmotic tablets of captopril. J.Pharm Sci Bioscientific Research.3(4):145-150.

The USP 26-National Formulary 21 Rockville MD US Pharmacopoeial Convention 2003.

Verma RK., Garg S., 2004. Development and evaluation of osmotically controlled oral drug delivery system of glipizide. Euro.J.Pharm.Biopharm.57:513-525.

Zenter GM., Rork GS., Himmelstein KJ., 1985.The controlled porosity osmotic pump. J control release; 1:269-282. 